\title{
Association of obesity with hypertension
}

\author{
Wilbert S. Aronow \\ Cardiology Division, Department of Medicine, Westchester Medical Center and New York Medical College, Valhalla, NY, USA \\ Correspondence to: Wilbert S. Aronow, MD, FACC, FAHA. Professor of Medicine, Cardiology Division, Westchester Medical Center and New York \\ Medical College, Macy Pavilion, Room 141, Valhalla, NY 10595, USA. Email: wsaronow@aol.com.
}

Submitted Jun 12, 2017. Accepted for publication Jun 21, 2017.

doi: 10.21037/atm.2017.06.69

View this article at: http://dx.doi.org/10.21037/atm.2017.06.69

Overweight is a body mass index between 25.0 to $29.9 \mathrm{~kg} / \mathrm{m}^{2}(1)$. Obesity is a body mass index of $30 \mathrm{~kg} / \mathrm{m}^{2}$ or higher (1). Obesity and obesity are risk factors for hypertension, dyslipidemia, and diabetes mellitus (2). The Framingham Study demonstrated that obesity was about twice as prevalent in obese men and in obese women as in men and in women with a normal Metropolitan relative weight (3). The Framingham Study also demonstrated that both men and women had an increase in blood pressure with increased overweight (4). Persons in the highest body mass index quartile had a $16 \mathrm{mmHg}$ higher systolic blood pressure and a $9 \mathrm{mmHg}$ higher diastolic blood pressure than persons in the lowest body mass index quartile (4). In this study, the systolic blood pressure increased $4 \mathrm{mmHg}$ for each $4.5 \mathrm{~kg}$ of increased weight (4). Insurance industry data have also shown a positive relationship between overweight or obesity with hypertension (5).

In 19,841 Canadians aged 18 to 74 years, the prevalence of hypertension in men and in women increased with increasing body mass index, especially in those aged 18 to 34 years (6). In the younger adults, men and women with a body mass index of more than $30 \mathrm{~kg} / \mathrm{m}^{2}$ had a 5 times higher prevalence of hypertension than persons with a body mass index less than $20 \mathrm{~kg} / \mathrm{m}^{2}$ (6). A cohort of 82,473 female nurses in the United States, aged 30 to 55 years were followed every 2 years since 1976 (7). In 1992, the body mass index was positively associated with the development of hypertension (7). Compared with a weight change of $2 \mathrm{~kg}$ or less, the risk of hypertension was $15 \%$ less in women who lost 5 to $9.9 \mathrm{~kg}, 26 \%$ less in women who lost $10 \mathrm{~kg}$ or more, increased $74 \%$ in women who gained 5 to $9.9 \mathrm{~kg}$, and increased 5.21 times in women who gained $25 \mathrm{~kg}$ or more (7).

In the nationwide Community Hypertension Evaluation Clinic screening of more than 1 million men and women, the prevalence of hypertension in overweight persons aged 20 to 39 years was twice that of persons with a normal weight and 3 times higher than that of underweight persons (8). In the overweight persons aged 40 to 64 years, the prevalence of hypertension was $50 \%$ higher than that of persons with a normal weight and $100 \%$ higher than that of underweight persons (8). In 22,354 Korean men and women, there was an association between body mass index and systolic and diastolic blood pressure over a body mass index range of 16 to $31 \mathrm{~kg} / \mathrm{m}^{2}(9)$. Attributable risk estimates from the Framingham Offspring Study of 2,027 men and 2,267 women aged 20 to 49 years followed for 8 years showed that obesity may be responsible for $78 \%$ of hypertension in men and for $65 \%$ of hypertension in women (10). Changes in body fat over 8 years were associated with changes in both systolic and diastolic blood pressure. Markedly obese women in their fourth decade had a 7 times increase in hypertension than did lean women of the same age (10).

The second Nurses' Health Study was a prospective cohort study of 83,882 women aged 27 to 44 years with a normal blood pressure who were followed for 14 years through 2005 for incident hypertension (11). The strongest risk factor for developing hypertension was an increased body mass index with obese women having a 4.7 times higher incidence of hypertension than did women with a body mass index less than $23.0 \mathrm{~kg} / \mathrm{m}^{2}$ (11). In this study, $40 \%$ of new hypertension cases were attributed to overweight or obesity, and $50 \%$ of new hypertension cases were attributable to a body mass index of $23 \mathrm{~kg} / \mathrm{m}^{2}$ or higher (11).

An analysis of data from 4 prospective studies in 6,328 persons that measured childhood and adult body mass index with a follow-up of 23 years demonstrated that overweight 
or obese children who were obese as adults increased the risk of hypertension 2.7 times (12). Becoming normal weight reduced the risk of developing hypertension to a level similar to persons who were never obese (12). The Cardiovascular Risk in Young Finns Study included 2,625 persons followed up for 21 to 27 years for the development of adult hypertension (13). This study showed that childhood overweight or obesity increased the risk of adult hypertension 1.65 times (13). The association between being overweight or obese with hypertension is even stronger for waist-to-hip ratio and computed tomographic measures of central fat distribution than is measurement of body mass index (14).

Obesity and overweight may have a major role in impairing renal pressure natriuresis in persons with chronic hypertension (15). Obesity increases sodium reabsorption in the kidneys and impairs renal pressure natriuresis by activating the renin-angiotensin and sympathetic nervous systems and by altering intrarenal physical forces (15). Chronic obesity also causes structural changes in the kidneys that cause a loss of nephron function, further increasing arterial pressure (15). The blood-pressure lowering effect of weight loss probably results from an improvement in insulin sensitivity and a reduction in sympathetic nervous system activity (14). Mechanisms for blood pressure reduction with weight loss in overweight hypertensive persons with a hypocaloric diet without a reduction in sodium intake are reduced sympathetic activity caused by a reduced activation of the renin-angiotensin-aldosterone system, natriuresis, contracted plasma volume, and reversal of the high cardiac output state (16).

Loss of weight in overweight persons lowers blood pressure (16). A meta-analysis of 18 studies showed that loss of $3 \%$ to $9 \%$ of body weight reduced systolic blood pressure $3 \mathrm{mmHg}$ and diastolic blood pressure $3 \mathrm{mmHg}$ (17). In the Trial of Nonpharmacological Interventions in the Elderly (TONE) study, a diet that reduced weight by $3.5 \mathrm{~kg}$ in persons aged 60 to 80 years of age with hypertension reduced blood pressure by 4.0/1.1 mmHg (18).

In the Trials of Hypertension Prevention, phase 1 study, 181 men and women aged 30 to 54 years old were randomized to 1 of 218 -month lifestyle interventions weight loss or dietary sodium restriction or to a usual care control group (19). After 7 years of follow-up, the incidence of hypertension was $18.9 \%$ in the weight loss group versus $40.5 \%$ in its control group and $22.4 \%$ in the sodium reduction group versus $32.9 \%$ in its control group. After logistic regression analysis, the odds of hypertension was reduced by $77 \%$ in the weight loss group and by $35 \%$ in the sodium reduction group compared with their control groups (19).

A meta-analysis was performed in 25 randomized controlled trials with 34 strata including 4,874 persons, mean age 37 to 66 years, investigating the effect of weight reduction on blood pressure (20). A reduction of $5.1 \mathrm{~kg}$ of body weight was associated with a reduction in systolic blood pressure of $4.44 \mathrm{mmHg}$ and in diastolic blood pressure of $3.57 \mathrm{mmHg}$ (20). In persons who lost more than $5 \mathrm{~kg}$, the reduction in systolic blood pressure was $6.63 \mathrm{mmHg}$, and the reduction in diastolic blood pressure was $5.12 \mathrm{mmHg}(20)$.

Bariatric surgery is an accepted treatment for obesity. A meta-analysis was performed of 3 studies reporting hypertension after bariatric surgery in 2 studies of 808 patients after gastric bypass and in 1 study of 247 patients after a gastric band (21). Remission of hypertension was defined as a blood pressure below $140 / 90 \mathrm{mmHg}$ without medications. The long-term remission rates for hypertension were $38.2 \%$ after gastric bypass and $17.4 \%$ after a gastric band (21). Bariatric surgery was performed in 87 black patients with morbid obesity, mean age 42 years (22). Of these patients, $74 \%$ had hypertension. The mean body mass index decreased from $57.1 \mathrm{~kg} / \mathrm{m}^{2}$ before surgery to $39.2 \mathrm{~kg} / \mathrm{m}^{2}$ at 1 year after bariatric surgery. Hypertension was resolved at 1 year after bariatric surgery in $45 \%$ of patients who had hypertension prior to bariatric surgery (22).

\section{Acknowledgements}

None.

\section{Footnote}

Conflicts of Interest: The author has no conflicts of interest to declare.

\section{References}

1. Cornier MA, Despres JP, Davis N, et al. Assessing adiposity. A scientific statement from the American Heart association. Circulation 2011;124:1996-2019.

2. Aronow WS, Fleg JL, Pepine CJ, et al. ACCF/AHA 2011 expert consensus document on hypertension in the elderly: a report of the American College of Cardiology 
Foundation Task Force on Clinical Expert Consensus Documents. Developed in collaboration with the American Academy of Neurology, American Geriatrics Society, American Society for Preventive Cardiology, American Society of Hypertension, American Society of Nephrology, Association of Black Cardiologists, and European Society of Hypertension. J Am Coll Cardiol 2011;57:2037-114.

3. Hubert HB, Feinleib M, McNamara PM, et al. Obesity as an independent risk factor for cardiovascular disease: a 26year follow-up of participants in the Framingham Heart Study. Circulation 1983:67:968-77.

4. Higgins M, Kannel W, Garrison R, et al. Hazards of obesity--the Framingham experience. Acta Med Scand Suppl 1988;723:23-36.

5. Harsha DW, Bray GA. Weight loss and blood pressure control (pro). Hypertension 2008;51:1420-5.

6. Rabkin SW, Chen Y, Leiter L, et al. Risk factor correlates of body mass index. Canadian Heart Health Surveys Research Group. CMAJ 1997;157:S26-31.

7. Huang Z, Willett WC, Manson JE, et al. Body weight, weight change, and risk for hypertension in women. Ann Intern Med 1998;128:81-8.

8. Stamler R, Stamler J, Riedlinger WF, et al. Weight and blood pressure. Findings in hypertension screening of 1 million Americans. JAMA 1978;240:1607-10.

9. Jones DW, Kim JS, Andrew ME, et al. Body mass index and blood pressure in Korean men and women: the Korean National Blood Pressure Survey. J Hypertens 1994;12:1433-7.

10. Garrison RJ, Kannel WB, Stokes J 3rd, et al. Incidence and precursors of hypertension in young adults: the Framingham Offspring Study. Prev Med 1987;16:235-51.

11. Forman JP, Stampfer MJ, Curhan GC. Diet and lifestyle risk factors associated with incident hypertension in women. JAMA 2009;302:401-11.

12. Juonala M, Magnussen CG, Berenson GS, et al. Childhood

Cite this article as: Aronow WS. Association of obesity with hypertension. Ann Transl Med 2017;5(17):350. doi: 10.21037/ atm.2017.06.69 adiposity, adult adiposity, and cardiovascular risk factors. $\mathrm{N}$ Engl J Med 2011;365:1876-85.

13. Juhola J, Oikonen M, Magnussen CG, et al. Childhood physical, environmental, and genetic predictors of adult hypertension: the cardiovascular risk in young Finns study. Circulation 2012;126:402-9.

14. Mertens IL, Van Gaal LF. Overweight, obesity, and blood pressure: the effects of modest weight reduction. Obes Res 2000;8:270-8.

15. Hall JE. The kidney, hypertension, and obesity. Hypertension 2003;41:625-33.

16. Reisin E, Frohlich ED. Effects of weight reduction on arterial pressure. J Chronic Dis 1982;35:887-91.

17. Mulrow CD, Chiquette E, Angel L, et al. Dieting to reduce body weight for controlling hypertension in adults. Cochrane Database Syst Rev 2000;(2):CD000484.

18. Whelton PK, Appel LJ, Espeland MA, et al. Sodium reduction and weight loss in the treatment of hypertension in older persons: a randomized controlled trial of nonpharmacological interventions in the elderly (TONE), TONE Collaborative Research Group. JAMA 1998;279:839-46.

19. He J, Whelton PK, Appel LJ, et al. Long-term effects of weight loss and dietary sodium reduction on incidence of hypertension. Hypertension 2000;35:544-9.

20. Neter JE, Stam BE, Kok FJ, et al. Influence of weight reduction on blood pressure. A meta-analysis of randomized controlled trials. Hypertension 2003;42:878-84.

21. Puzziferri N, Roshek TB 3rd, Mayo HG, et al. Longterm follow-up after bariatric surgery. A systematic review. JAMA 2014;312:934-42.

22. Onyewu SC, Ogundimu OO, Ortega G, et al. Bariatric surgery outcomes in black patients with super morbid obesity: a 1-year postoperative review. Am J Surg 2017;213:64-8. 